Article

\title{
Trend Analyses of Extreme Precipitation Events in the Yarlung Zangbo River Basin, China Using a High-Resolution Precipitation Product
}

\author{
Jiao Fan ${ }^{1,2,3}$, Wenchao Sun ${ }^{1,2,3, *}$, Yong Zhao ${ }^{2, *(\mathbb{B})}$, Baolin Xue ${ }^{1,3} \mathbb{1}^{\mathbb{D}}$, Depeng Zuo ${ }^{1,3}$ \\ and Zongxue $\mathrm{Xu}^{1,3}$ \\ 1 College of Water Sciences, Beijing Normal University, Xinjiekouwai Street 19, Beijing 100875, China; \\ fan_jiao@163.com (J.F.); xuebl@bnu.edu.cn (B.X.); dpzuo@bnu.edu.cn (D.Z.); zxxu@bnu.edu.cn (Z.X.) \\ 2 State Key Laboratory of Simulation and Regulation of Water Cycle in River Basin, China Institute of Water \\ Resources and Hydropower Research, Beijing 100038, China \\ 3 Beijing Key Laboratory of Urban Hydrological Cycle and Sponge City Technology, Xinjiekouwai Street 19, \\ Beijing 100875, China \\ * Correspondence: sunny@bnu.edu.cn (W.S.); zhaoyong@iwhr.com (Y.Z.); Tel.: +86-10-6225-1121 (W.S.); \\ +86-10-6878-1617 (Y.Z.)
}

Received: 29 March 2018; Accepted: 27 April 2018; Published: 2 May 2018

\begin{abstract}
The Yarlung Zangbo River Basin (YZRB) is an important transboundary river basin in Tibet, China with south Asian countries. Changes in precipitation are important driving factors of river flow changes. Extreme Precipitation Events (EPE), in particular, have serious impacts on human life and sustainable development. The objective of this study is to explore the temporal changes and the spatial distribution of EPE over the YZRB in recent decades using a precipitation product with a $5 \mathrm{~km}$ spatial resolution and the Mann-Kendall nonparametric statistical test method. A more thorough understanding of the spatial heterogeneity in precipitation was expected from using this high resolution dataset. At both basin and pixel scale, both annual precipitation amounts and number of rain days had significant upward trends, indicating that the increase in the number of rain days is one possible cause of the annual precipitation amounts increases. The annual precipitation and number of rain days increased significantly in $50.8 \%$ and $75.8 \%$ of the basin area, respectively. The areas showing upward trends for the two indexes mostly overlapped, supporting the hypothesis that the increasing number of rain days is one possible cause of the increases in annual precipitation in these areas. General precipitation intensity and EPE intensity increased in the Lhasa regions and in the southern part of the lower-reach region. However, the intensity of general precipitation and EPE decreased in the Nyangqu River Basin. A total of $43.0 \%$ of the area in the YZRB exhibits significant upward trends in EPE frequency. The contributions of EPE to total rainfall increase significantly in the Lhasa and Shannan regions. Overall, it was shown that the risk of disasters from EPE in the YZRB increases in the eastern middle-reach region and southern lower-reach region.
\end{abstract}

Keywords: Yarlung Zangbo River Basin; Extreme Precipitation Events; temporal trends; high resolution precipitation product

\section{Introduction}

According to the Fifth Intergovernmental Panel on Climate Change (IPCC) Assessment Report, there is conclusive evidence that the Earth is becoming warmer. Since the middle of the twentieth century, many extreme weather events have been observed [1]. The IPCC Special Report on Managing the Risks of Extreme Events and Disasters to Advance Climate Change Adaptation noted that Extreme Precipitation Events (EPE) in Asia will increase, but that probabilities for, and trends in, EPE in different 
regions will vary, making it necessary to analyze the situation at the regional scale [2]. In recent years, under the background of global warming, many researchers have explored the spatial variability and temporal trends in EPE. Iwashima and Yamamoto made an early study of this field [3]. Changes in EPE have been confirmed in many areas [4-6]. Most studies found that a decrease of precipitation will not lead to a decrease in EPE. However, the relationship between precipitation and EPE is not simple, and in some regions, precipitation increases, but EPE decreases [7]. Compared with the variations in general precipitation, the changes in EPE are more complex [8]. EPE will increase at the global and regional scale in the future, which will cause significant damage to agriculture, ecosystems, and infrastructure, and cause a great loss of human life and property [9-11]. Therefore, the extreme values of precipitation provide more valuable information than average values for disaster prevention.

The Yarlung Zangbo River Basin (YZRB) is located in the Tibetan Plateau (TP), which has a similar climate to the Polar Regions because of its high elevation and was found to have an increase trend in annual precipitation in the latter half of the last century [12]. The YZRB is sensitive to climate change and has a fragile ecosystem. The river is the highest in the world, and provides the second largest amount of hydropower in China. The river is the main source of freshwater for Tibet and for the downstream countries of India and Bangladesh. Because of climate change and the importance of the YZRB, precipitation changes in the YZRB are an important research topic. An increase in the frequency of extreme precipitation events over the period 1910 to 2000 in India, which is adjacent to YZRB, was confirmed by Sen Roy and Balling [13]. Several studies have analyzed the trends in precipitation at monthly and annual scales [14-18]. However, studies on the changes in EPE are limited. Sang et al. [19] assessed the trends of intensity and frequency of EPE (using a daily precipitation of $>25 \mathrm{~mm}$ ) in the middle and eastern part of the basin. All of the above-mentioned research used data from meteorological stations. However, the in situ precipitation gauging network is sparse in the YZRB. Because of the basins' high elevation and its topographical complexity, the spatial heterogeneity of precipitation is high within the basin. The complexity of relationships between extreme daily precipitation and topography in mountainous regions has been shown in several studies [20]. It is possible that the data from the limited stations may not reflect the conditions in YZRB with sufficient accuracy. Reliable, high resolution, gridded precipitation datasets are needed for better understanding the spatial heterogeneity of precipitation in the YZRB.

With the development of meteorological satellites, the inversion technique for precipitation data collection using microwave and infrared satellite observations has been rapidly developed. At present, many precipitation products are available, such as the TRMM (Tropical Rainfall Measuring Mission) [21] and CMORPH (Climate prediction center MORPHing technique) [22] satellite precipitation products, and some Chinese integrated precipitation products such as FY-2 (Feng Yun 2) [23] and NMIC (National Meteorological Information Center) [24]. Some researchers have applied these products to the analysis of precipitation in China. Shen et al. [25] examined the performance of six high-resolution satellite precipitation estimates over China from 2005 to 2007, and concluded that they all can adequately capture the overall spatial distribution and temporal variations of precipitation. Guo et al. [26] evaluated three common satellite precipitation products as well as their gauge-corrected counterparts. The products that were corrected by site data performed better. Dong et al. [27] used a gridded Chinese ground precipitation dataset, with a resolution of $0.5^{\circ}$, released by the National Meteorological Information Center, in the analyses of EPE in arid areas in northwest China. The result showed that the grid data are better than the in situ gauged data for precipitation trend analysis.

The objective of the present study is to analyze the temporal trends and the spatial distribution of the EPE in YZRB for the past five decades using a satellite-based precipitation dataset with $5 \mathrm{~km}$ spatial resolution, and the Mann-Kendall trend analysis method. The results of this study will be valuable for providing decision-support information for flood control and water resources management under the background of climate change in the YZRB and in downstream countries. The paper is organized as follows. The study basin and data used are introduced in the next section, followed by the approach 
used for the Mann-Kendall trend analysis. Then, the results of the trend analysis are discussed and, finally, conclusions are drawn.

\section{Data and Methods}

\subsection{Study Area}

The YZRB is located in the southwest part of the TP (Figure 1), which is known as the third Pole of the world [28], the Asian water towers [29], and the best laboratory for global climate change [30]. These three phrases vividly capture the ecological sensitivity and environmental vulnerability of the YZRB, as well as the necessity for, and benefits of, research there. The river flows from west to east through the Ngari, Shigatse, Lhasa, Nagqu and Shannan municipal administrative regions, and then flows to India. The length of the river is about $2057 \mathrm{~km}$. The basin area is about $242,000 \mathrm{~km}^{2}$ and the annual runoff is about 166.1 billion $\mathrm{m}^{3}$, and is the major fresh water source of Tibet [31].

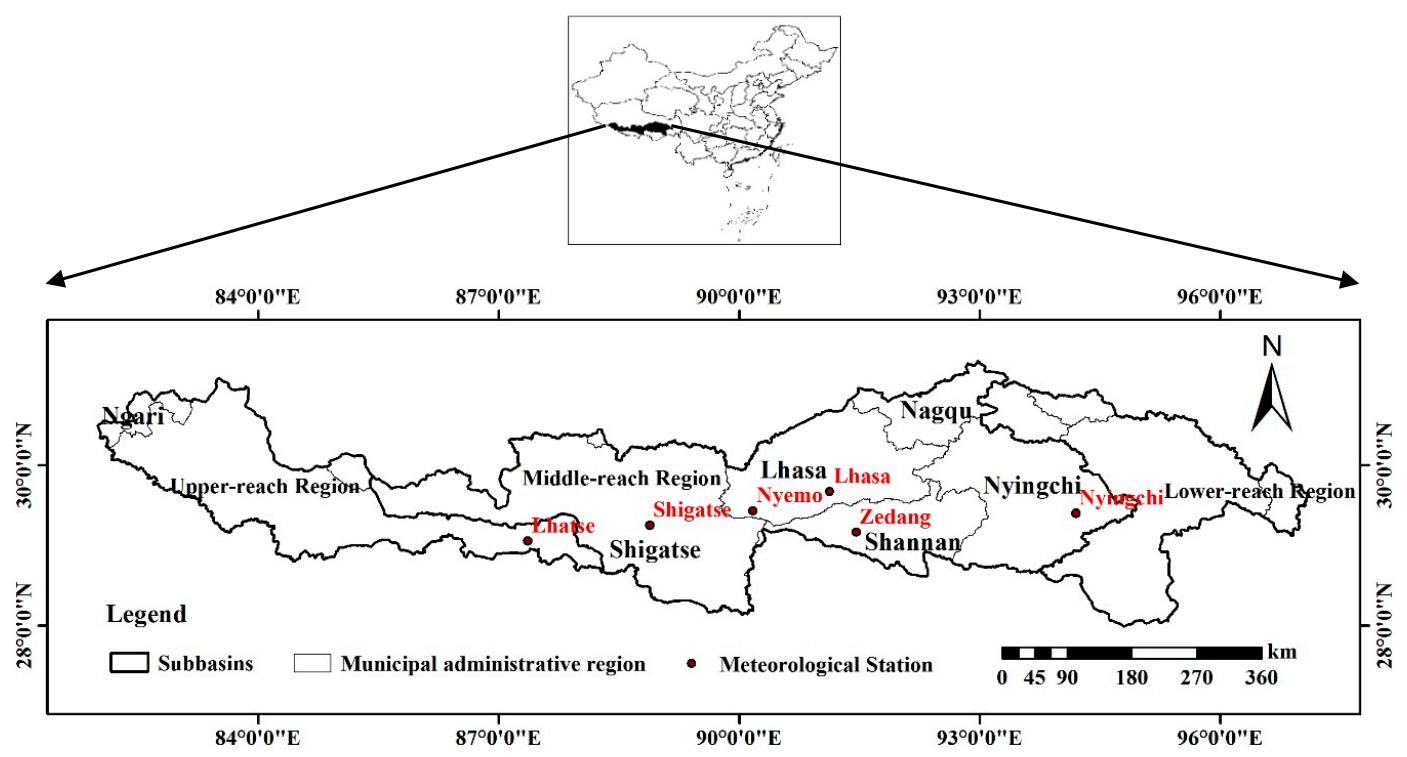

Figure 1. The YZRB and its location in China.

From the upper-reach to the lower-reach regions of YZRB, there are six major tributaries: the Dogxung Zangbo, Nyangqu, Lhasa, Nyang, Yigong Zangbo and Purlung Zangbo Rivers. The elevation ranges from about 7000 to $150 \mathrm{~m}$ (Figure 2). The boundary points between the upper and middle, and the middle and lower reaches, are Lhaze and Nuxia, respectively.

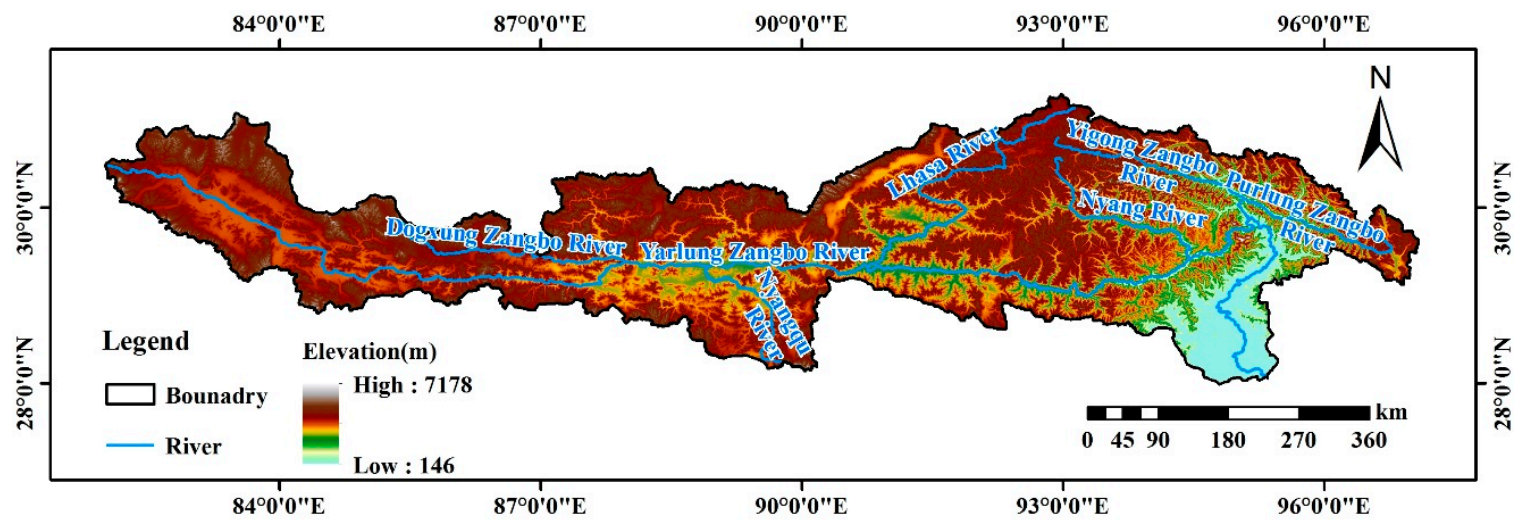

Figure 2. Topography and river system of the YZRB. 


\subsection{Data}

A satellite-based, multi-source, precipitation dataset (1958-2010) with a $5 \mathrm{~km}$ spatial and $3 \mathrm{~h}$ temporal resolution, developed by the Land-Atmosphere Interaction Research Group at Sun Yat-sen University, China (http://globalchange.bnu.edu.cn/home) was used in the present study. This dataset combines gauged precipitation observations and existing gridded precipitation data, including remote sensing products and reanalysis data. The dataset was constructed in two steps: first, gauged observations from China Meteorological Administration was used as the response variable, and the precipitation trend surface was estimated by a thin-plate smoothing spline and a gridded precipitation field as explanatory variables. Then, the correlated residual field was corrected by modified Cressman weight to ensure that the interpolated precipitation is close to observations. This dataset has high accuracy and high spatial resolution. The methodology for producing the dataset can be found in [32]. The dataset for the period 1958-2010 was used to analyze the trend of EPE in the YZRB. Figure 3 shows a comparison of ground gauged data and gridded data for averaged daily precipitation for six meteorological stations covering the upper-, middle-, and lower-reach regions. The relative error ranges from around $-13 \%$ to $6 \%$, thus indicating that the differences are small and acceptable. In the central Tibetan Plateau, there is an application of using the dataset to force the Noah-MP (Noah with MultiParameterization options) land model in the study of Gao et al. [33]. In their study, the dataset was compared with another dataset developed at the Institute of Tibetan Plateau Research, Chinese Academy of Sciences (available at: http: //dam.itpcas.ac.cn/data/User_Guide_for_China_Meteorological_Forcing_Dataset.htm), for which the spatial resolution is 0.1 degree. Their results show that the two datasets have similar accuracy, but the spatial resolution of the dataset we used in this study is higher.

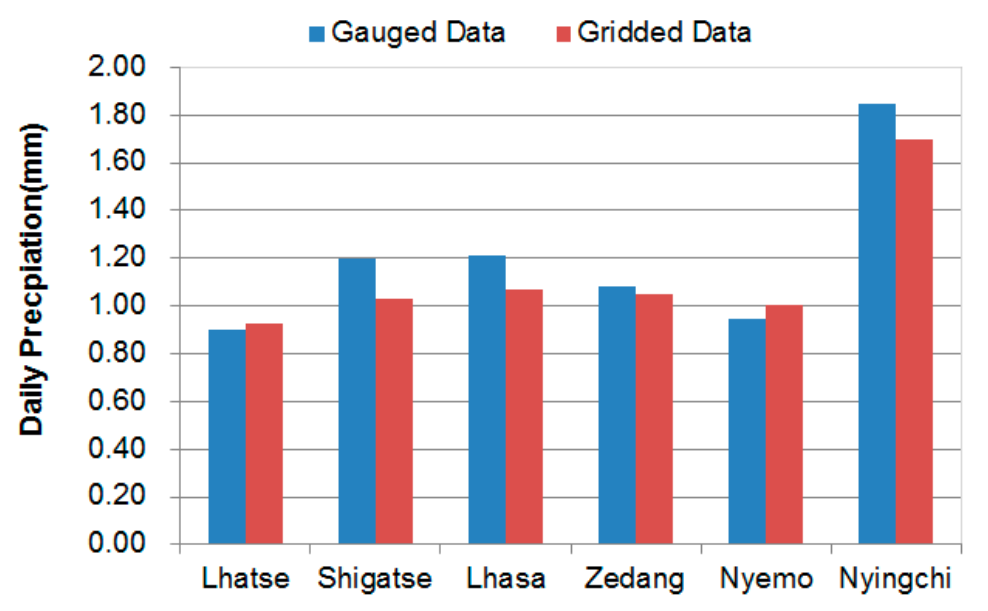

Figure 3. Comparison of gauged and gridded precipitation data at six sites.

\subsection{General and Extreme Precipitation Indexes}

In this study, most indexes are selected from Core Indices of STARDEX (STAtistical and Regional dynamical Downscaling of EXtremes for European regions, https://crudata.uea.ac.uk/projects/ stardex/). Three indexes (annual precipitation (AP), rainfall days (RD), and rainfall intensity (RI)) were used to analyze the temporal variations of general precipitation. Four indexes used in the Statistical and Region Dynamical Downscaling of Extreme for European Regions Project were chosen to analyze the characteristics of EPE [34]. These four indexes comprised, two intensity indexes (PX5D, PQ90), a frequency index (PNL90), and an index indicating the contribution of extreme precipitation to total precipitation (PFL90). Every index was computed annually for the period 1958-2010, and then the interannual variability of these values was used to indicate the changes of EPE in the YZRB under climate change. The definitions of all seven indexes are shown in Table 1. 
Table 1. Definitions of precipitation indexes used in this study.

\begin{tabular}{ccc}
\hline Indexes & Definitions & Units \\
\hline AP & Annual precipitation & $\mathrm{mm}$ \\
RD & The number of rain days in a year & $\mathrm{d}$ \\
RI & The ratio of AP and RD in a year & $\mathrm{mm} / \mathrm{d}$ \\
PX5D & Annual maximum consecutive five-day precipitation in a year & $\mathrm{mm}$ \\
PQ90 & The 90th percentile of daily precipitation in a year & $\mathrm{mm}$ \\
PNL90 & Number of rain days in a year for which daily precipitation > long-term PQ90 & $\mathrm{d}$ \\
PFL90 & The ratio of precipitation for days in a year for when daily precipitation $>$ & $\%$ \\
& long-term PQ90 to annual precipitation & $\%$ \\
\hline
\end{tabular}

\subsection{Methodology}

The Mann-Kendall test $[35,36]$ is one of the most widely used nonparametric tests to detect significant trends in precipitation time series [37]. In this study, the Mann-Kendall test was employed to analyze the monotonic trend of the changes in precipitation and EPE indexes for the period 1958-2010. The purpose of the text was to reveal the cumulative effects of climate change over long temporal scales. For time series data $X=\left\{x_{1}, x_{2}, \ldots, x_{n}\right\}$, the test statistic $S$ is computed as

$$
S=\sum_{i=1}^{n-1} \sum_{j=i+1}^{n} \operatorname{sgn}\left(x_{j}-x_{i}\right),
$$

where

$$
\operatorname{sgn}\left(x_{j}-x_{i}\right)= \begin{cases}1, & x_{j}<x_{i} \\ 0, & x_{j}=x_{i} . \\ -1, & x_{j}>x_{i}\end{cases}
$$

Assuming that the data are independent and identically distributed, the mean and variance of the $S$ statistic are given by

$$
\begin{gathered}
E(S)=0 \\
\operatorname{VAR}(S)=n(n-1)(2 n-15) / 18 .
\end{gathered}
$$

Considering the existence of tied ranks (equal observations) in the data, the variance of $S$ is updated as

$$
\operatorname{VAR}(S)=\left[n(n-1)(2 n-15)-\sum_{i=1}^{m} t_{i}\left(t_{i}-1\right)\left(2 t_{i}+5\right)\right] / 18,
$$

where $m$ is the number of tied groups, and $t_{i}$ is the number of data in the $i$ th tied group. For a sample size $>10$, the standardized normal statistic $Z$ is estimated as

$$
Z= \begin{cases}\frac{S-1}{\sqrt{\operatorname{VAR}(S)},}, & S>0 \\ 0, & S=0 \\ \frac{S+1}{\sqrt{\operatorname{VAR}(S)},}, & S<0\end{cases}
$$

A comparison between $\mathrm{Z}$ and the standard normal variate at the desired significance level $\alpha$, allows the significance of the trend to be tested. In this study, a significance level of $5 \%$ was selected, which means that, if $|Z|>1.96$, the null hypothesis of no trend would be rejected.

For those pixels for which the trend in index values is significant $(p<0.05)$, the magnitude of changes per year can be computed using Sen's slope estimator [38]. The true slope (change per unit time) can be calculated as

$$
\theta=\operatorname{Median}\left(\frac{x_{j}-x_{i}}{j-i}\right), i<j
$$




\section{Results}

\subsection{Changes in AP and EPE at the Basin Scale}

We analyzed the linear trend of seven indexes at the basin scale. The results are shown in Table 2. The time series of general precipitation indexes analysis over the YZRB are shown in Figure 4. Both AP and RD passed the 95\% confidence level in significance tests, and showed an increasing trend of $1.47 \mathrm{~mm} / \mathrm{a}$ and $0.404 \mathrm{~d} / \mathrm{a}$, respectively, which indicated that both the annual precipitation amount and the number of rain days increased. However, the RI showed no significant change as AP and RD increased.
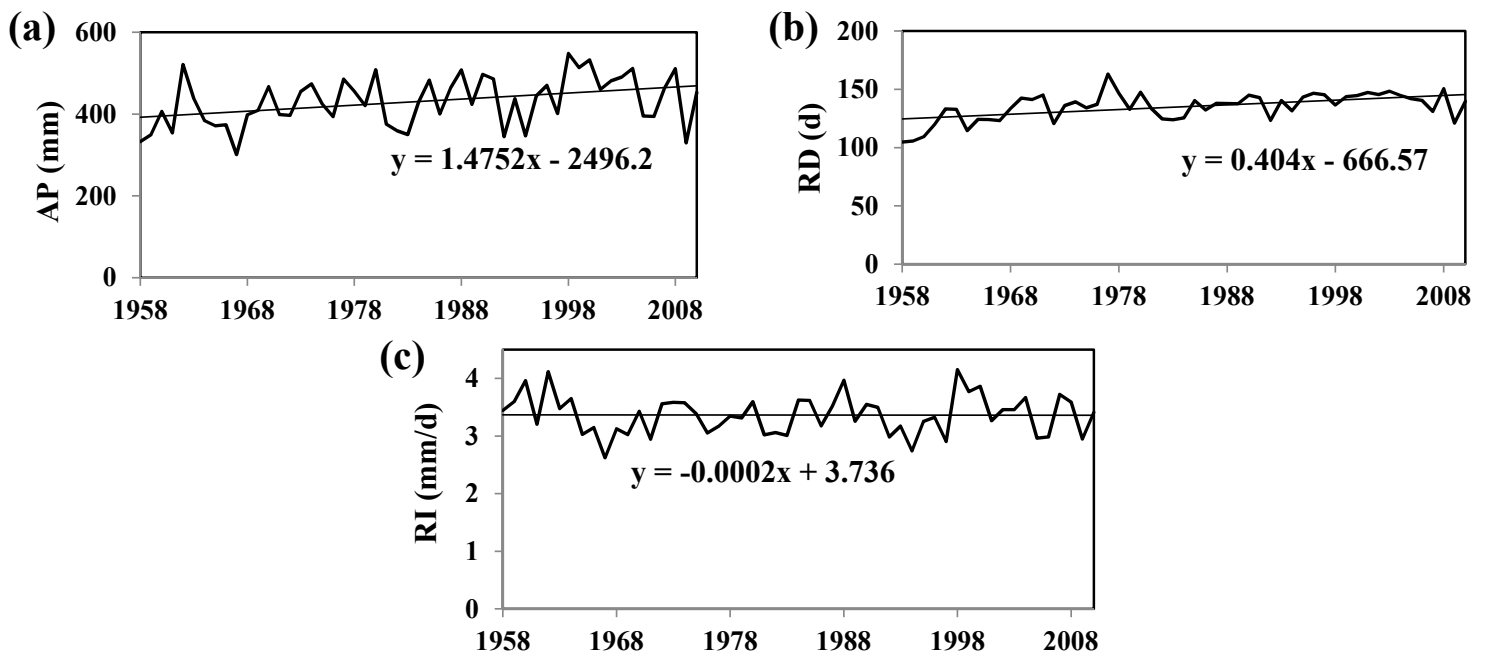

Figure 4. Basin-scale (a) AP, (b) RD, and (c) RI time series and linear trend lines for 1958-2010.

Table 2. The detected trend in the seven general and extreme precipitation indexes.

\begin{tabular}{cccc}
\hline Indexes & Average Value & Trend & Significant or Not \\
\hline AP & $430.6 \mathrm{~mm}$ & $1.4752 \mathrm{~mm} / \mathrm{a}$ & YES \\
RD & $135.0 \mathrm{~d}$ & $0.404 \mathrm{~d} / \mathrm{a}$ & YES \\
RI & $3.4 \mathrm{~mm} / \mathrm{d}$ & $-0.0002 \mathrm{~mm} / \mathrm{a}$ & $\mathrm{NO}$ \\
PX5D & $46.0 \mathrm{~mm}$ & $0.0319 \mathrm{~mm} / \mathrm{a}$ & $\mathrm{NO}$ \\
PQ90 & $6.9 \mathrm{~mm}$ & $0.0047 \mathrm{~mm} / \mathrm{a}$ & $\mathrm{NO}$ \\
PNL90 & $13.5 \mathrm{~d}$ & $0.0811 \mathrm{~d} / \mathrm{a}$ & YES \\
PFL90 & $30.5 \%$ & $0.0727 \% / \mathrm{a}$ & NO \\
\hline
\end{tabular}

Figure 5 shows the time series for the four EPE indexes. The two indexes of intensity (PX5D and PQ90) and the index showing the contributions of EPE to annual precipitation (PFL90) present an increase in trends of $0.0319 \mathrm{~mm} / \mathrm{a}, 0.0047 \mathrm{~mm} / \mathrm{a}$, and $0.0727 \% / \mathrm{a}$, respectively. However, the detected three increasing trends are not significant at a 0.05 confidence level. Only the trend of the index showing EPE days (PNL90) is significant, which increased at a rate of about $0.0811 \mathrm{~d} / \mathrm{a}$.
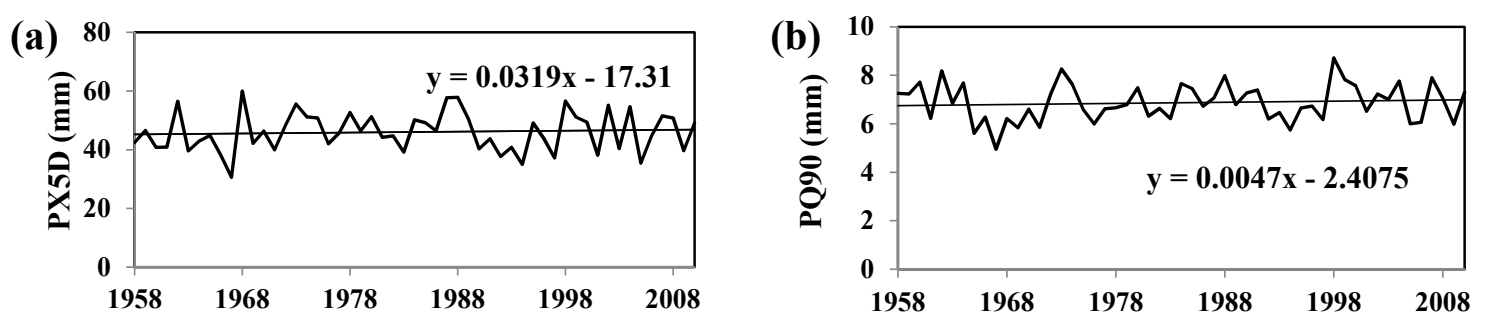

Figure 5. Cont. 
(c)

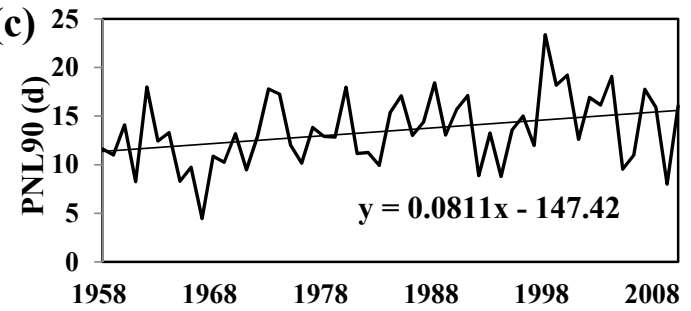

(d)

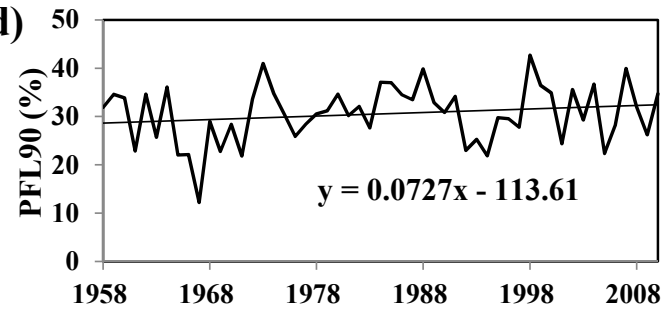

Figure 5. Basin-scale time series and their linear trend lines for (a) PX5D, (b) PQ90, (c) RNL90, and (d) PFL90 for 1958-2010.

\subsection{General Precipitation Indexes: Spatial Distribution and Temporal Changes}

Figure 6 presents the spatial distribution of average AP, RD and RI in the YZRB for the period of 1958-2010. All three indexes generally exhibit a similar spatial pattern; the values increased from the west of the upper-reach region to the east of the lower-reach region. The only exception was the Nyangqu River Basin and its adjacent region to the north of the mainstream, where the RD was lower and RI was higher than in the surrounding area. The minimum rainfall was $167 \mathrm{~mm}$ in the source area. Most of the middle-reach region belongs to a wet-to-dry transitional zone, with rainfall between $300 \mathrm{~mm}$ and $400 \mathrm{~mm}$ per year. The RD generally increased from west $(79.7 \mathrm{~d})$ to east $(187.6 \mathrm{~d})$, but a low value area occurred in the middle-reach region, with a value of 90-100 d. The RI increased from the upper-reach $(1.93 \mathrm{~mm} / \mathrm{d})$ to the lower-reach region $(4.00 \mathrm{~mm} / \mathrm{d})$. However, the highest value of $4.18 \mathrm{~mm} / \mathrm{d}$ was detected in the Shigatse region in the middle-reach region.

The spatial distribution of detected significant changes in AP, RD, and RI are shown in Figure 7. An increasing trend in AP was found in $50.8 \%$ of the basin area, with a maximum magnitude of $5.09 \mathrm{~mm} / \mathrm{a}$. This area is mainly located in the middle upper-reach, west middle-reach, and lower-reach regions. Pixels with a decreasing trend are located in the west of the upper-reach region, and cover $1.37 \%$ of the basin area. More than $75.8 \%$ of the area exhibits an increasing trend in RD. Only a limited number of pixels in the upper-reach region $(0.9 \%$ of the total area) show downward trends. There is an upward trend in RI in some parts of the Lhasa River Basin and the lower-reach region near the basin outlet while the Nyang River Basin in the Shigatse region has a decreasing trend.
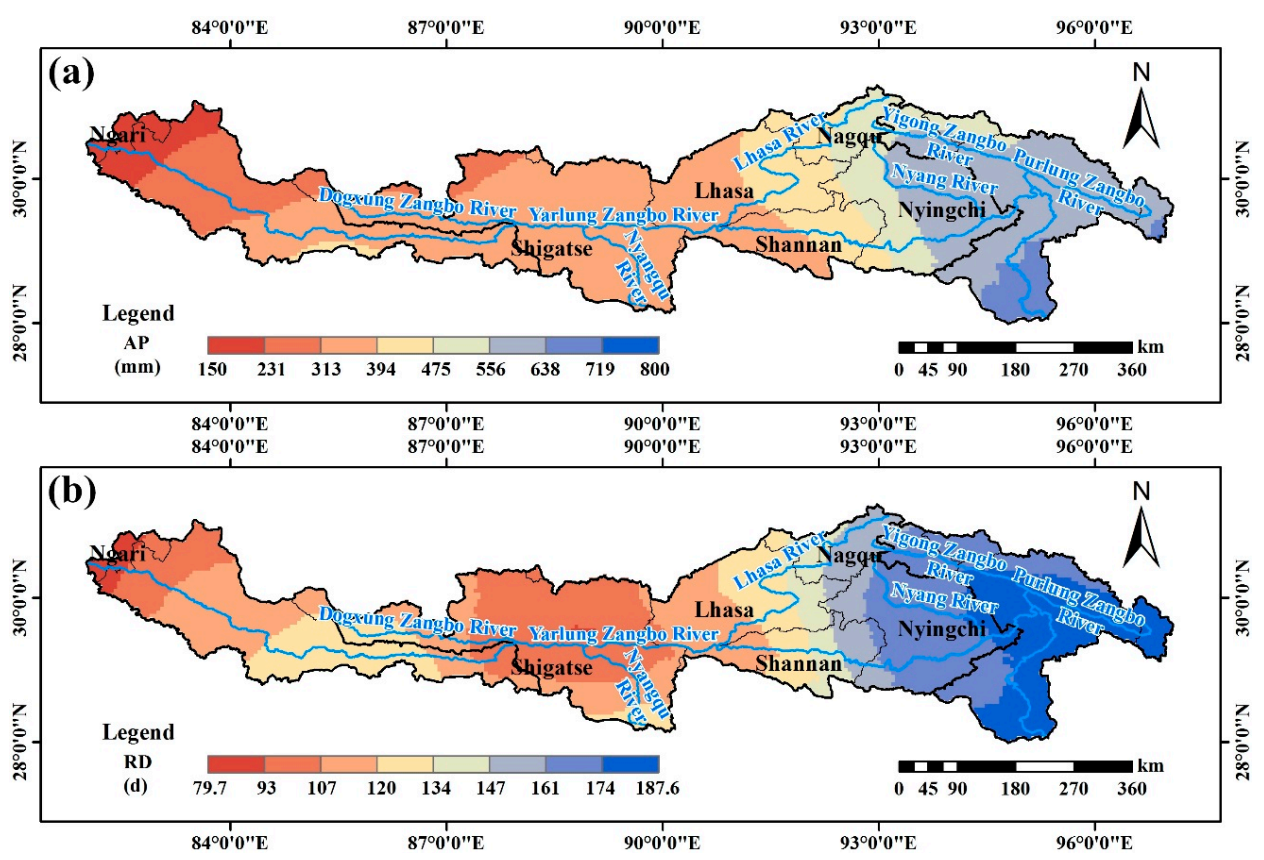

Figure 6. Cont. 


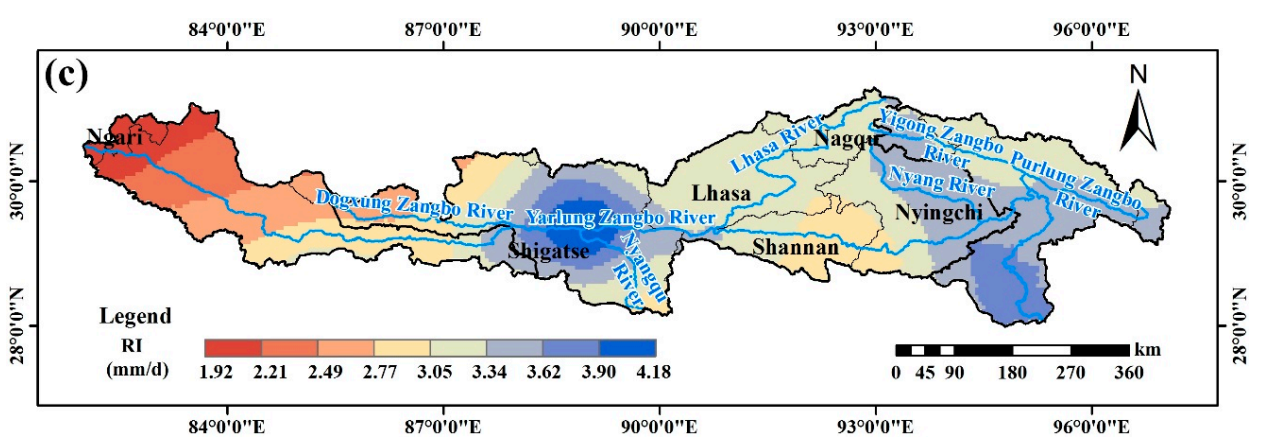

Figure 6. Spatial distribution of average (a) AP; (b) RD; and (c) RI for the period of 1958-2010.
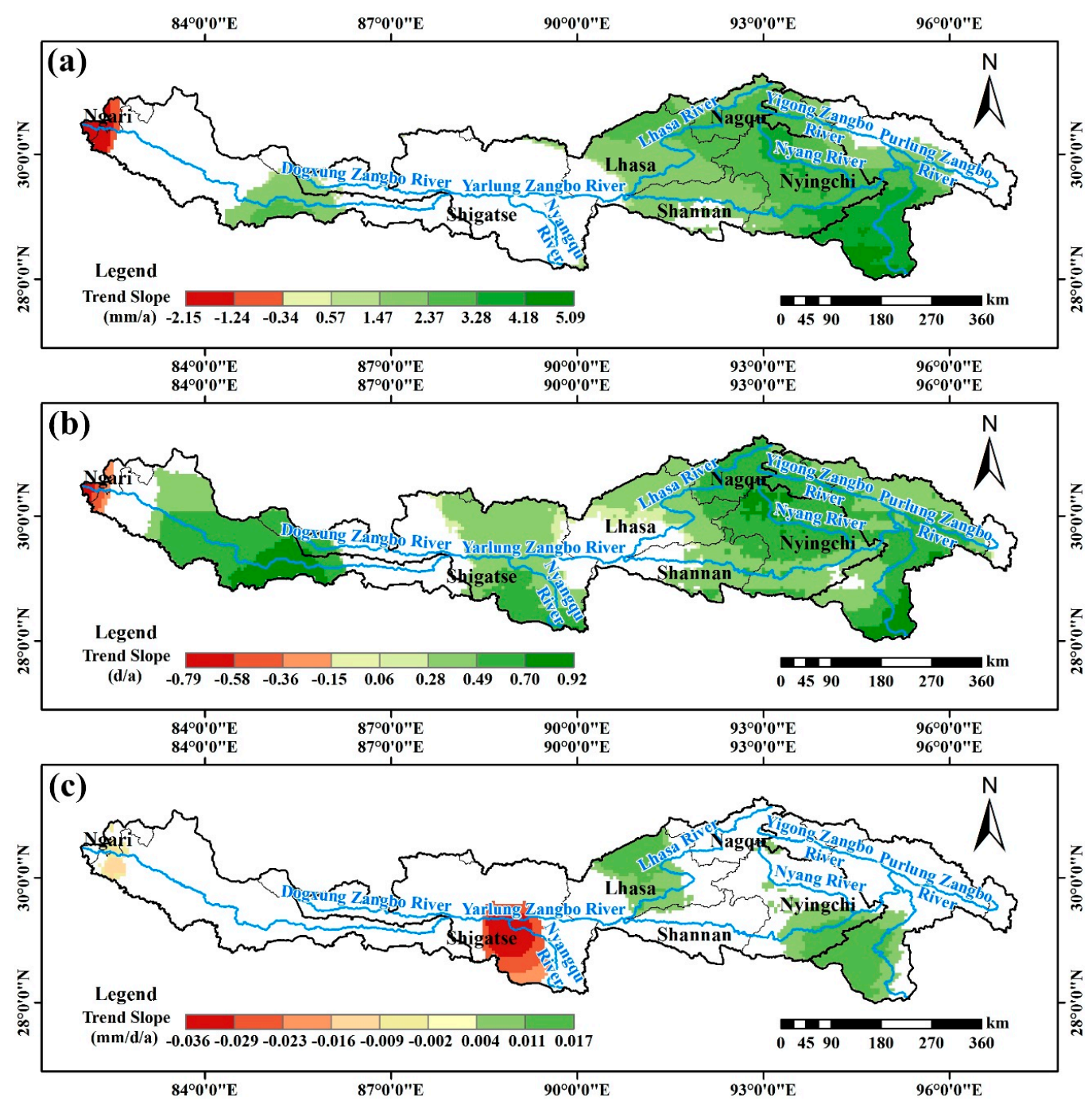

Figure 7. Changes in (a) AP; (b) RD; and (c) RI for 1958-2010.

\subsection{Spatial Distribution and Temporal Changes of EPE Indexes}

Figure 8 shows the spatial distribution of the two EPE intensity indexes, PX5D and PQ90, for 1958-2010. Both indexes exhibit similar spatial patterns. Generally, the values increase from the upper-reach region to the lower-reach region, with the exception of the Nyangqu River Basin and its surrounding area in the middle-reach region. The minimum PX5D value of $24.5 \mathrm{~mm}$ was found in the headwater region and the maximum value of $63.0 \mathrm{~mm}$ was detected near the basin outlet. 
Values of some pixels in the Shigatse region in the middle reach region were also relatively high, ranging from about 50 to $60 \mathrm{~mm}$. High values for the PQ90 index were detected in Shigatse, in the middle-reach region and the basin outlet region. PX5D pixels with upward trends are mainly located in the Lhasa River Basin, the southeast corner of the middle-reach region, and the southwest corner of the lower-reach region, and cover $24.6 \%$ of the YZRB area (Figure 9a). However, many of the PX5D pixels in the Nyangqu River Basin show decreasing trends. The spatial patterns of changes in PQ90 (Figure $9 \mathrm{~b}$ ) are similar to those of PX5D. About 38.3\% of the basin area shows a significant trend, and $33.0 \%$ of the basin area has an increasing trend. These evaluations indicate that the magnitude of EPE in Lhasa (the most developed and populated region in the basin) is increasing. Correspondingly, the magnitude of flood in this region may increase, as the two indexes, especially PX5D, could capture heavy rains of several days, inducing flooding to occur [39].
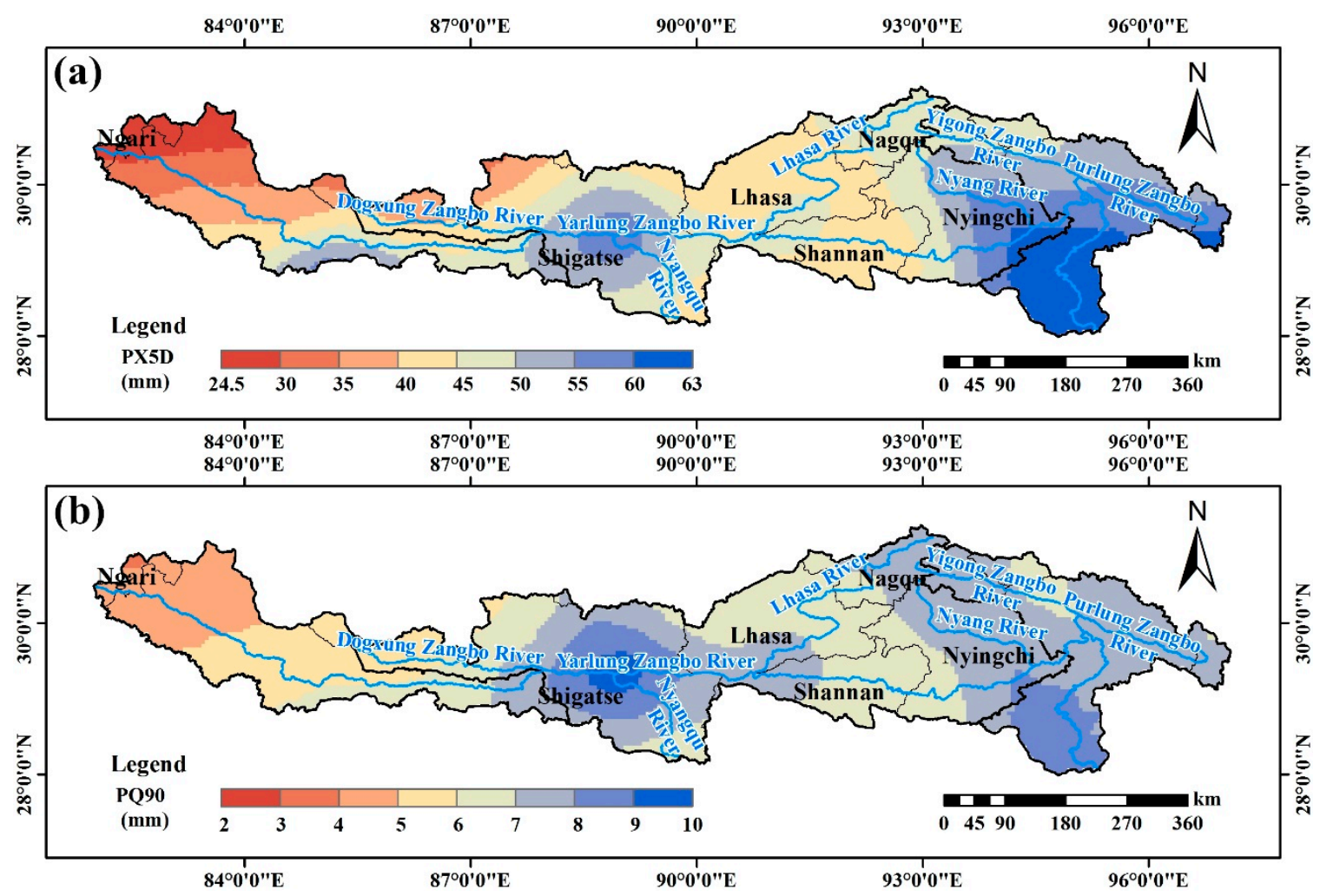

Figure 8. Spatial distribution of average (a) PX5D; and (b) PQ90 for 1958-2010.

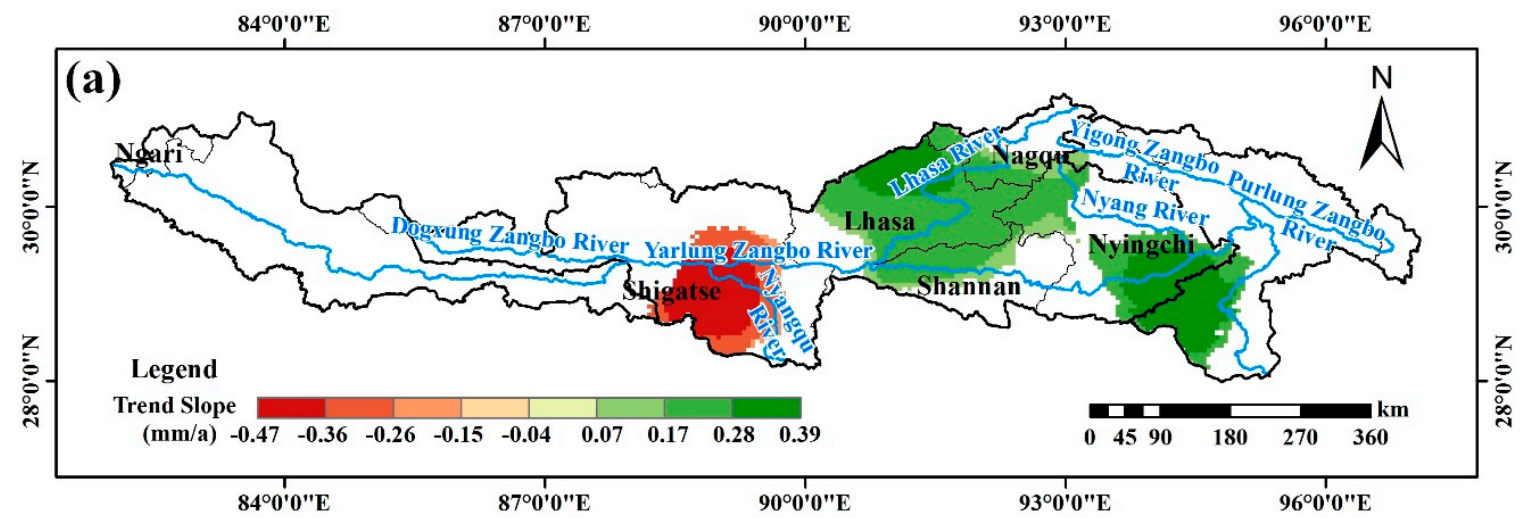

Figure 9. Cont. 


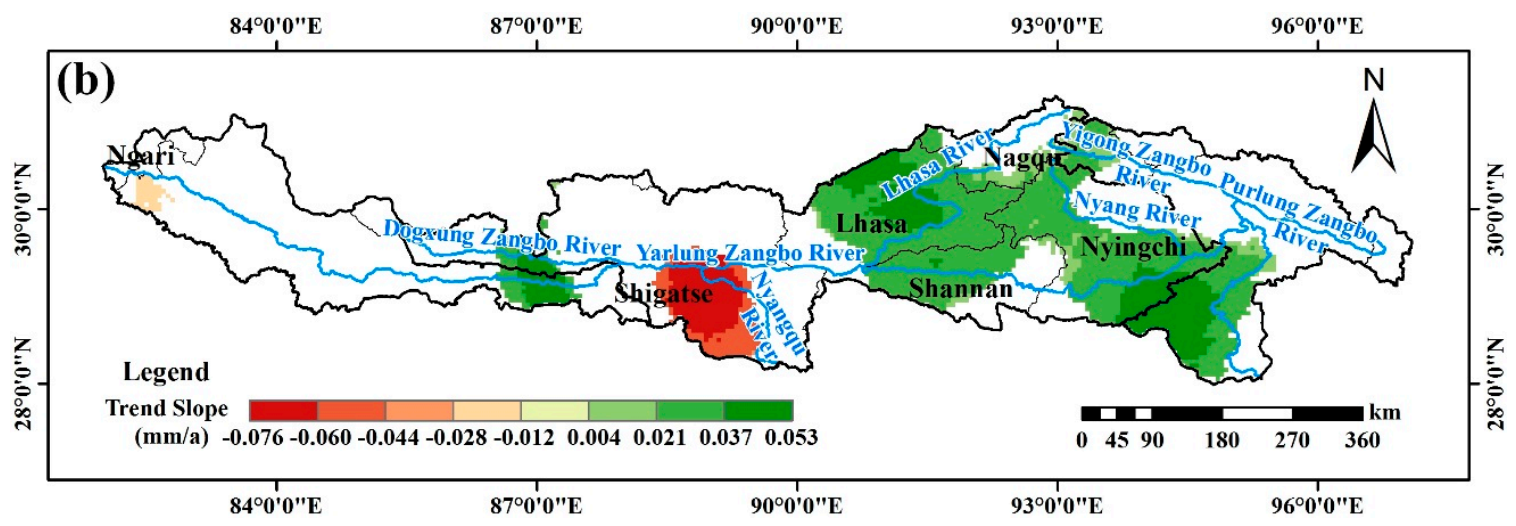

Figure 9. Changes in (a) PX5D; and (b) PQ90 for 1958-2010.

The PNL90 index indicates the frequency of EPE. Figure 10 shows the PNL90 spatial distribution and trends for the YZRB. From the headwater region to the basin outlet, PNL90 increased gradually, with the exception of Shigatse in the middle-reach region, where the value is lower than $10 \mathrm{~d}$. The general spatial pattern resembles the one pattern detected by Yang et al. [40]. A significant trend occurs in $43.0 \%$ of the YZRB, of which nearly $99 \%$ show increasing trends. This indicates that there is a possibility of increasing EPE in most parts of the basin.

The PFL90 index characterizes the contributions of EPE to annual rainfall. Figure 11a demonstrates that the values are highest (36.3\%) in the southern edge of the upstream region. The value is lowest $(27.2 \%)$ in Lhasa. About $34.2 \%$ of the basin area shows significant upward trends, ranging from 0 to $0.49 \% / \mathrm{a}$. These areas are located near the boundary between the upper- and the middle-reach regions, the eastern part of the middle-reach region, and the southern part of the lower-reach region. However, in the Nyangqu River Basin, downward trends are detected.
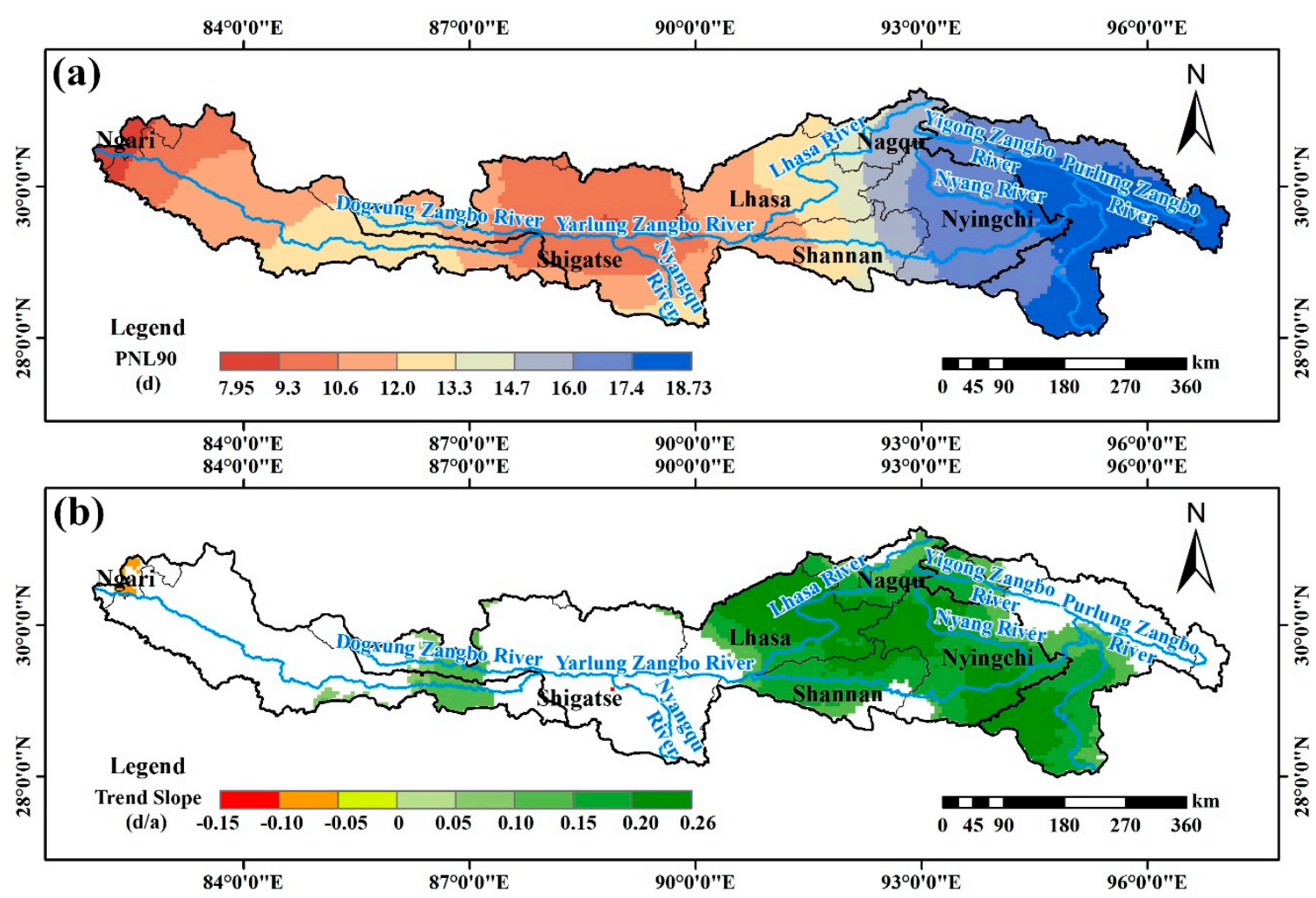

Figure 10. PNL90 (a) spatial distribution (b) and changes for 1958-2010. 

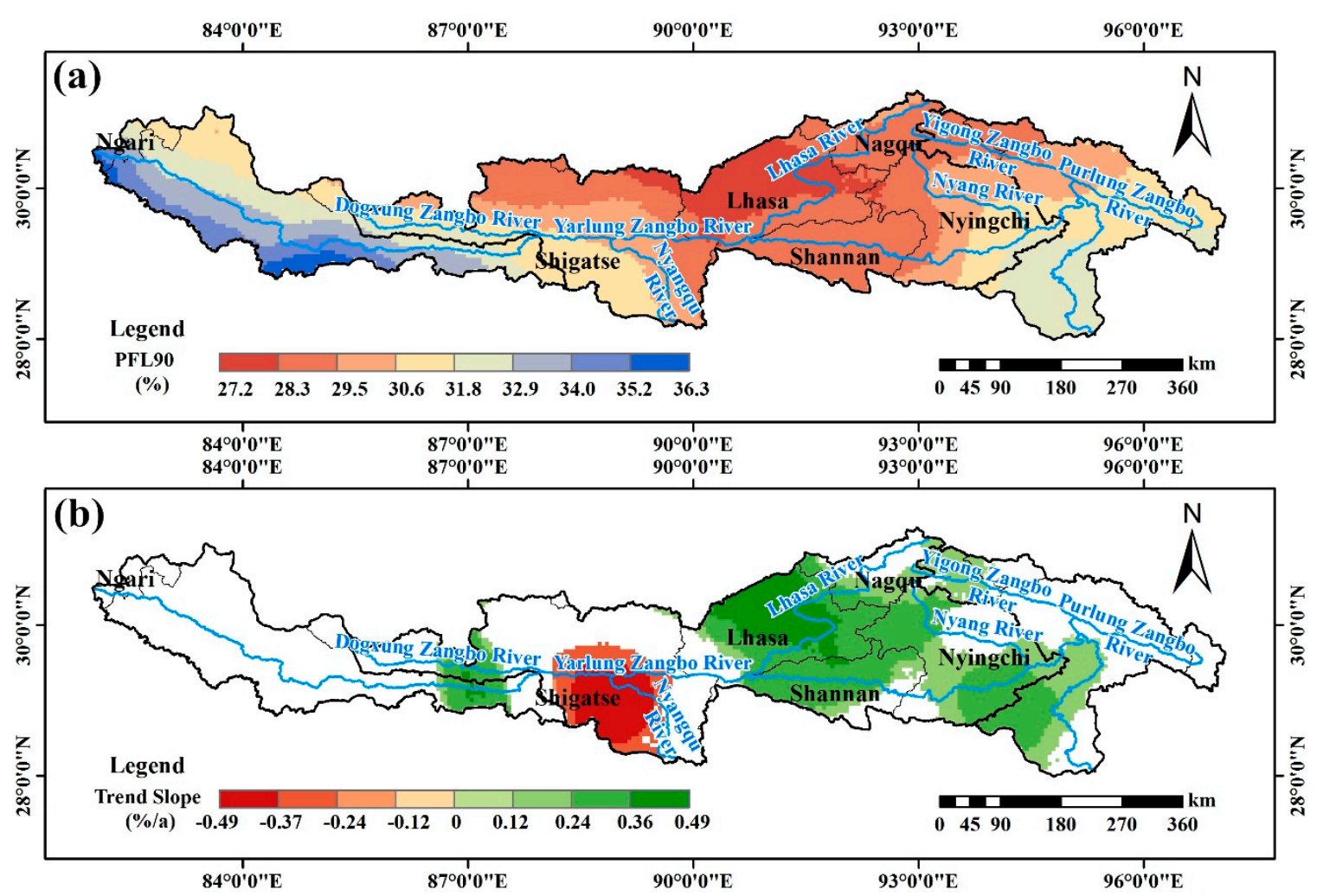

Figure 11. PFL90 (a) spatial distribution and (b) changes for 1958-2010.

\section{Discussion}

The annual precipitation for the whole basin has an increasing trend, which is in accordance with the results of You et al. [41] and Liu et al. [18]. The number of rain days at the basin scale shows a significant increasing trend. However, there are no significant upward or downward trends for RI. It can be inferred from these results that the increase in AP arises from the increase in $\mathrm{RD}$, and not from the increase of RI. At the pixel scale, around $50 \%$ of the basin area presents upward trends in AP. This percentage is lower than that obtained by $\mathrm{Xu}$ et al. [16], and can be explained by the fact that the period and the source of data for the analyses are different. The pixels with increasing trends for AP are mostly overlapped by pixels with increasing trends for RD. This suggests that the increase in RD is the most likely explanation for the upward trend in AP for these pixels.

Our results show that the EPE intensity decreased from the lower-reach region to the upper-reach region. However, Shigatse, in the middle-reach region, is an exception. Here, the EPE intensity is higher than the surrounding area and does not follow the general spatial distribution, indicating that other factors, such as local topography, may also have an influence on precipitation at smaller spatial scales. The magnitude and frequency in the western middle-reach region and the lower-reach region generally show upward trends. This is in contrast to the results obtained by Sang et al. [19]. One possible explanation for the differences in results is the fact that time series data used in our study covered a longer period (1958-2010 vs. 1973-2011). Another possible explanation for the differences in the result from the two studies could be that the definitions of EPE used in the two studies are different. In Sang et al. [19], an EPE is defined as daily precipitation greater than $25 \mathrm{~mm}$. In our study, we defined the 90 quantile of daily precipitation in a year as the threshold of EPE. The definition of events based on percentile values can better reflect the spatial heterogeneity. The results from our studies do show a spatial difference in EPE intensity. The wide spatial coverage of the satellite-based data allows knowledge of EPE to be obtained for the upper-reach region and west lower-reach region, which were not covered in previous studies because of the limited availability of gauging station data. 
When combining the knowledge of intensity, frequency, and contribution to precipitation, the disaster risk associated with EPE increases in the eastern part of the middle-reach region and the southern part of the lower-reach region. More studies are needed to evaluate the hydrological implication of the increasing trends in EPE in these regions.

\section{Conclusions}

In this study, seven indexes were computed to examine the characteristics of EPE in the YZRB, the highest river basin in the world, using a satellite-based precipitation dataset with a spatial resolution of $5 \mathrm{~km}$. The temporal trends in these indexes at both basin scale and pixel scale were evaluated. The use of high spatial resolution data improved the description of spatial heterogeneity in EPE, when compared with previous studies. The results show that, at the basin scale, the annual precipitation, number of rain days and number of EPE is increasing. The annual precipitation and number of rain days increased significantly in $50.8 \%$ and $75.8 \%$ of the basin area, respectively. The areas showing upward trends for the two indexes mostly overlapped, indicating that the increasing number of rain days is one possible reason for the increases in annual precipitation. General precipitation intensity and EPE intensity increased in the Lhasa and the southern part of the lower-reach region. However, in general, they decreased in the Nyangqu River Basin. There was a significant upward trend in EPE frequency in $43.0 \%$ of the basin area. The contribution of EPE to rainfall increased significantly in Lhasa and Shannan. In summary, when information regarding the intensity, frequency, and amount of precipitation was combined, it revealed that the risk of EPE to cause disasters increased in the eastern part of the middle-reach region and the south part of the lower-reach region. The findings of this study will provide valuable information for supporting decision-making in flood disaster prevention and water sources management in the YZRB and downstream countries.

Author Contributions: W.S., Y.Z. and Z.X. designed the idea and methodology; J.F. and B.X. collected and processed the original data; J.F. and D.Z. did the analysis; J.F. and W.S. wrote the paper.

Acknowledgments: This study was supported by the National Natural Science Foundation of China (grant nos. 91647202, 41671018, 51679006), National Key Research and Development Program of China (grant no. 2016YFC0401308), and Open Research Fund of State Key Laboratory of Simulation and Regulation of Water Cycle in River Basin (China Institute of Water Resources and Hydropower Research), grant no. IWHR-SKL-201703.

Conflicts of Interest: The authors declare no conflict of interest.

\section{References}

1. Stocker, T.F.; Qin, D.; Plattner, G.-K.; Tignor, M.M.B.; Allen, S.K.; Boschung, J.; Nauels, A.; Xia, Y.; Bex, V.; Midgley, P.M. Climate Change 2013-The Physical Science Basis; Cambridge University Press: Cambridge, UK, 2013; ISBN 978-92-9169-138-8.

2. Aguilar, M.A.; Del Mar Saldana, M.; Aguilar, F.J. Generation and quality assessment of stereo-extracted DSM from GeoEye-1 and WorldView-2 imagery. IEEE Trans. Geosci. Remote Sens. 2014, 52, 1259-1271. [CrossRef]

3. Iwashima, T.; Yamamoto, Y. Notes and correspondence: A statistical analysis of the extreme events: Long-term trend of heavy daily precipitation. J. Meteorol. Soc. Jpn. Ser. II 1993, 71, 637-640. [CrossRef]

4. Klein Tank, A.M.G.; Peterson, T.C.; Quadir, D.A.; Dorji, S.; Zou, X.; Tang, H.; Santhosh, K.; Joshi, U.R.; Jaswal, A.K.; Kolli, R.K.; et al. Changes in daily temperature and precipitation extremes in central and south Asia. J. Geophys. Res. 2006, 111, D16105. [CrossRef]

5. Zolina, O.; Simmer, C.; Gulev, S.K.; Kollet, S. Changing structure of European precipitation: Longer wet periods leading to more abundant rainfalls. Geophys. Res. Lett. 2010, 37. [CrossRef]

6. Kunkel, K.E.; Easterling, D.R.; Redmond, K.; Hubbard, K. Temporal variations of extreme precipitation events in the United States: 1895-2000. Geophys. Res. Lett. 2003, 30. [CrossRef]

7. Liu, M.; Xu, X.; Sun, A.Y.; Wang, K.; Liu, W.; Zhang, X. Is southwestern China experiencing more frequent precipitation extremes? Environ. Res. Lett. 2014, 9. [CrossRef] 
8. Li, Z.; He, Y.; Wang, P.; Theakstone, W.H.; An, W.; Wang, X.; Lu, A.; Zhang, W.; Cao, W. Changes of daily climate extremes in southwestern China during 1961-2008. Glob. Planet. Chang. 2012, 80-81, 255-272. [CrossRef]

9. Li, J.; Zhang, Q.; Chen, Y.D.; Xu, C.Y.; Singh, V.P. Changing spatiotemporal patterns of precipitation extremes in China during 2071-2100 based on Earth System Models. J. Geophys. Res. Atmos. 2013, 118, 12537-12555. [CrossRef]

10. Zhang, Q.; Sun, P.; Singh, V.P.; Chen, X. Spatial-temporal precipitation changes (1956-2000) and their implications for agriculture in China. Glob. Planet. Chang. 2012, 82-83, 86-95. [CrossRef]

11. Scholz, G.; Quinton, J.N.; Strauss, P. Soil erosion from sugar beet in Central Europe in response to climate change induced seasonal precipitation variations. Catena 2008, 72, 91-105. [CrossRef]

12. Zhai, P.; Zhang, X.; Wan, H.; Pan, X. Trends in total precipitation and frequency of daily precipitation extremes over China. J. Clim. 2005, 18, 1096-1108. [CrossRef]

13. Roy, S.S.; Balling, R.C. Trends in extreme daily precipitation indices in India. Int. J. Climatol. 2004, 24, 457-466. [CrossRef]

14. Cao, J.; Qin, D.; Kang, E.; Li, Y. River discharge changes in the Qinghai-Tibet Plateau. Chin. Sci. Bull. 2006, 51, 594-600. [CrossRef]

15. You, Q.; Kang, S.; Wu, Y.; Yan, Y. Climate change over the Yarlung Zangbo River Basin during 1961-2005. J. Geogr. Sci. 2007, 17, 409-420. [CrossRef]

16. Xu, Z.X.; Gong, T.L.; Li, J.Y. Decadal trend of climate in the Tibetan plateau-Regional temperature and precipitation. Hydrol. Process. 2008, 22, 3056-3065. [CrossRef]

17. Tong, K.; Su, F.; Yang, D.; Zhang, L.; Hao, Z. Tibetan Plateau precipitation as depicted by gauge observations, reanalyses and satellite retrievals. Int. J. Climatol. 2014, 34, 265-285. [CrossRef]

18. Liu, Z.; Yao, Z.; Huang, H.; Wu, S.; Liu, G. Land use and climate changes and their impacts on runoff in the Yarlung Zangbo River Basin, China. Land Degrad. Dev. 2014, 25, 203-215. [CrossRef]

19. Sang, Y.F.; Singh, V.P.; Gong, T.; Xu, K.; Sun, F.; Liu, C.; Liu, W.; Chen, R. Precipitation variability and response to changing climatic condition in the Yarlung Tsangpo River Basin, China. J. Geophys. Res. 2016, 121, 8820-8831. [CrossRef]

20. Prudhomme, C.; Reed, D.W. Relationships between extreme daily precipitation and topography in a mountainous region: A case study in Scotland. Int. J. Climatol. 1998, 18, 1439-1453. [CrossRef]

21. Huffman, G.J.; Bolvin, D.T.; Nelkin, E.J.; Wolff, D.B.; Adler, R.F.; Gu, G.; Hong, Y.; Bowman, K.P.; Stocker, E.F. The TRMM Multisatellite Precipitation Analysis (TMPA): Quasi-global, multiyear, combined-sensor precipitation estimates at fine scales. J. Hydrometeorol. 2007, 8, 38-55. [CrossRef]

22. Al, J.E.T.; Joyce, R.J.; Janowiak, J.E.; Arkin, P.A.; Xie, P. CMORPH: A method that produces global precipitation estimates from passive microwave and infrared data at high spatial and temporal resolution. J. Hydrometeorol. 2004, 5, 487-503. [CrossRef]

23. Shi, C.; Xie, Z. A time downscaling scheme of precipitation by using geostationary meteorological satellite data. Progress Geogr. 2008, 27, 15-22, (In Chinese with English Abstract).

24. Pan, Y.; Shen, Y.; Yu, J.; Zhao, P. Analysis of the combined gauge-Satellite hourly precipitation over China based on the OI technique. Acta Meteorol. Sin. 2012, 70, 1381-1389, (In Chinese with English Abstract).

25. Shen, Y.; Xiong, A.; Wang, Y.; Xie, P. Performance of high-resolution satellite precipitation products over China. J. Geophys. Res. Atmos. 2010, 115. [CrossRef]

26. Guo, H.; Chen, S.; Bao, A.; Hu, J.; Yang, B.; Stepanian, P.M. Comprehensive evaluation of high-resolution satellite-based precipitation products over China. Atmosphere 2016, 7, 6. [CrossRef]

27. Dong, L.; Zhang, M.; Wang, S.; Zhu, X.; Ren, Z.; Wang, Q. Extreme precipitation events in arid areas in northwest China based on gridded data. J. Natural Resour. 2014, 29, 2048-2057, (In Chinese with English Abstract).

28. Lu, L.; Bian, L.; Zhang, Z. Climate change and its impact on the polar and the Tibetan Plateau regions. Chin. J. Polar Res. 2011, 23, 82-89, (In Chinese with English Abstract).

29. Immerzeel, W.W.; van Beek, L.P.H.; Bierkens, M.F.P. Climate change will affect the Asian water towers. Science 2010, 328, 1382-1385. [CrossRef] [PubMed]

30. Pan, B.; Li, J. Qinghai-Tibetan Plateau: A driver and amplifier of the global climatic change. J. Lanzhou Univ. 1996, 32, 108-115. (In Chinese with English Abstract).

31. Liu, C.; Zhou, C.; Yu, J.; Li, L.; Zhang, Y. Zhongguo Shui Wen Di Li; Science Press: Beijing, China, 2014. 
32. Huang, C.; Zheng, X.; Tait, A.; Dai, Y.; Yang, C.; Chen, Z.; Li, T.; Wang, Z. On using smoothing spline and residual correction to fuse rain gauge observations and remote sensing data. J. Hydrol. 2014, 508, 410-417. [CrossRef]

33. Gao, Y.; Li, K.; Chen, F.; Jiang, Y.; Lu, C. Assessing and improving Noah-MP land model simulations for the central Tibetan Plateau. J. Geophys. Res. 2015, 120, 9258-9278. [CrossRef]

34. Haylock, M.R.; Goodess, C.M. Interannual variability of European extreme winter rainfall and links with mean large-scale circulation. Int. J. Climatol. 2004, 24, 759-776. [CrossRef]

35. Mann, H.B. Nonparametric tests against trend. Econometrica 1945, 13, 245-259. [CrossRef]

36. Kendall, M.G. Rank Correlation Methods; Charles Griffin: London, UK, 1948.

37. Li, Z.; Zheng, F.; Liu, W.; Flanagan, D.C. Spatial distribution and temporal trends of extreme temperature and precipitation events on the Loess Plateau of China during 1961-2007. Quat. Int. 2010, 226, 92-100. [CrossRef]

38. Sen, P.K. Estimates of the regression coefficient based on Kendall's tau. J. Am. Stat. Assoc. 1968, 63, 1379-1389. [CrossRef]

39. Nandintsetseg, B.; Greene, J.S.; Goulden, C.E. Trends in extreme daily precipitation and temperature near Lake Hövsgöl, Mongolia. Int. J. Climatol. 2007, 27, 341-347. [CrossRef]

40. Yang, Z.; Jian, J.; Hong, J. Temporal and spatial distribution of extreme precipitation events in Tibet during 1961-2010. Plateau Meteorol. 2014, 33, 37-42, (In Chinese with English Abstract).

41. You, Q.L.; Kang, S.C.; Yan, Y.P.; Xu, Y.W.; Zhang, Y.J.; Huang, J. Trends in daily temperature and precipitation extremes over the Yarlung Zangbo River Basin during 1961-2005. J. Geogr. Sci. 2009, 64, 592-600. (In Chinese with English Abstract).

(C) 2018 by the authors. Licensee MDPI, Basel, Switzerland. This article is an open access article distributed under the terms and conditions of the Creative Commons Attribution (CC BY) license (http:/ / creativecommons.org/licenses/by/4.0/). 